\title{
PRIMENA MODIFIKOVANOG ELEKTRIČNOG LUKA ZA ZAVARIVANJE KORENOG PROLAZA CEVI OD AUSTENITNIH NERĐAJUĆIH ČELIKA
}

\author{
Rradomir Jovičić1, \\ Olivera Popović ${ }^{2}$ \\ Radica Prokić Cvetković2 \\ Meri Burzić, \\ Zijah Burzić3
}

\author{
${ }^{1}$ Univerzitet u Beogradu, \\ Inovacioni centar, \\ Beograd, Srbija \\ 2Univerzitet u Beogradu, \\ Mašinski fakultet, \\ Beograd, Srbija \\ ${ }^{3}$ Vojnotehnički institut, \\ Beograd, Srbija
}

Correspondence:

Radomir Jovičić

e-mail:

rjovicic@mas.bg.ac.rs

\section{Rezime:}

Do sada su se za zavarivanje cevi od visokolegiranih austenitnih čelika koristili TIG i E postupci. Ove postupke odlikuju mala brzina zavarivanja i veliki unos toplote, zbog čega su zavareni spojevi pokazivali sklonost ka nastanku određenih vrsta grešaka, pa je i produktivnost zavarivanja bila niska. Primenom modifikovanog električnog luka bitno se povećava produktivnost zavarivanja i smanjuje se verovatnoća pojave grešaka u zavarenim spojevima. U radu su cevi od austenitnog nerđajućeg čelika zavarene u tri prolaza, pri čemu je, radi poređenja, koreni prolaz zavaren modifikovanim lukom i klasičnim MIG postupkom. S obzirom na to da je zavarivanje korenog prolaza najsporija faza u izradi zavarenog spoja, primenom modifikovanog luka dnevni obim zavarivačkih radova može se povećati u odnosu na primenu klasičnog MIG postupka za oko 17\%, u odnosu na primenu TIG postupka za oko 30\%, i u odnosu na primenu E postupka za 70 do $80 \%$.

Ključne reči:

zavarivanje, modifikovani električni luk, austenitni nerđajući čelik, produktivnost.

\section{UVOD}

U grupu nerđajućih čelika ubrajaju se čelici koji su hemijski ili elektrohemijski postojani pri delovanju vlažne atmosfere, vodene pare, kao i pojedinih kiselina i baza, njihovih soli i vodenih rastvora. Zajednička karakteristika nerđajućih čelika je povećani sadržaj hroma. Hrom povećava korozionu postojanost čelika u različitim sredinama, naročito u oksidacionim. Nerđajući čelici mogu imati austenitnu, feritnu i martenzitnu strukturu.

Čelik X5CrNi18-8 jedan je od najšire primenjivanih austenitnih nerđajućih čelika. Koristi se u prehrambenoj, tekstilnoj, faramaceutskoj i hemijskoj industriji zbog dobre korozione postojanosti i sposobnosti deformacije. Nedostatak mu je nizak napon tečenja, što ograničava njegovu upotrebu za noseće konstrukcije. Austenitna mikrostruktura ovog čelika prikazana je na Slici 1 . U poređenju sa niskougljeničnim konstrukcionim čelicima, austenitni nerđajući čelici imaju: za oko $100{ }^{\circ} \mathrm{C}$ nižu tačku topljenja, za oko $20 \%$ veću specifičnu toplotu, tri puta manju toplotnu provodnost, i za 50\% veći koeficijent linearnog toplotnog širenja [1]. 
Veća specifična toplota povećava količinu toplote potrebnu da se čelik zagreje do tačke topljenja. Međutim, manja toplotna provodnost i niža tačka topljenja smanjuju količinu toplote potrebnu za topljenje čelika. Zbog toga se austenitni čelici zavaruju sa manjim unosima toplote u odnosu na niskougljenične čelike. Veći koeficijent linearnog širenja povećava deformacije austenitnih čelika pri zavarivanju, u odnosu na niskougljenične konstrukcione čelike. Ove deformacije mogu se smanjiti pravilnim redosledom zavarivanja i smanjenjem unosa toplote.

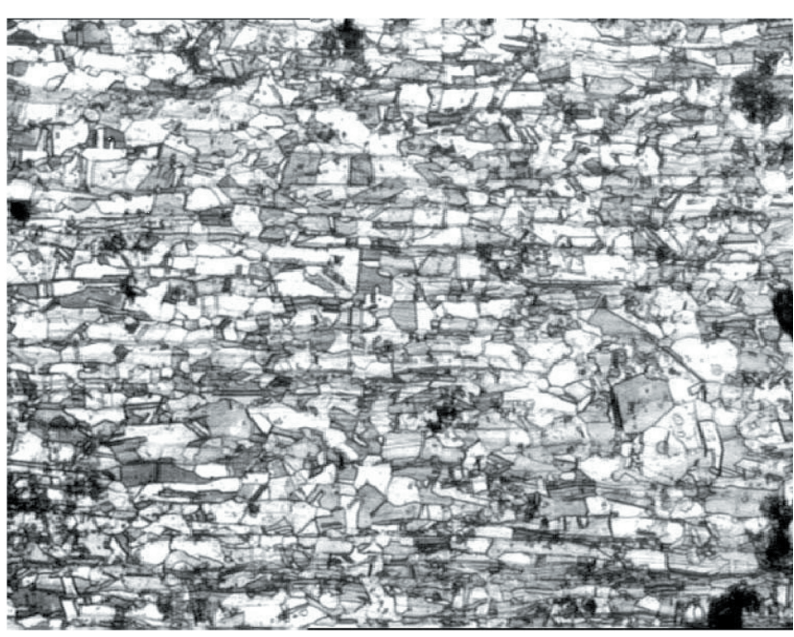

Slika 1. Austenitna mikrostruktura čelika X5CrNi 18-8.

U poređenju sa drugim čelicima, austenitni čelici skloniji su obrazovanju toplih prslina u zavarenim spojevima. Razlozi za to su: veliki naponi koji deluju na zavareni spoj pri njegovom očvršćavanju, a koji su posledica male toplotne provodnosti i velikog koeficijenta linearnog širenja čelika, usmerenost primarne dendritne strukture metala šava (MŠ) i pojava lako topivih faza [2]. Često povećanje udela osnovnog materijala (OM) u MŠ povećava njegovu sklonost ka pojavi toplih prslina zbog povećanja sadržaja elemenata kao što su P i S i elemenata koji obrazuju lako topive faze. Zbog toga se bira režim zavarivanja koji omogućava smanjenje udela OM u MŠ.

Na smanjenje sklonosti ka pojavi toplih prslina može se uticati još i smanjenjem napona koji deluju na MŠ u trenutku njegovog očvršćavanja. Ovi naponi mogu se smanjiti izborom šavova sa malim koeficijentom oblika tj. plitkih i širokih šavova sa malom dubinom uvarivanja i izborom optimalne temperature predgrevanja.

\section{POSTUPCI ZAVARIVANJAAUSTENITNIH ČELIKA}

Tehnološke zahteve koji se pojavljuju pri zavarivanju cevi većih prečnika, izrađenih od austenitnih nerđajućih čelika, moguće je ispuniti primenom E, MIG i TIG postupaka zavarivanja.

Kod E postupka, za razliku od ostalih navedenih postupaka, nije potrebna zaštita naličja korenog dela spoja. Troska prekriva naličje korena šava, štiti ga od kontakta sa vazduhom i omogućava formiranje glatkog korena sa postepenim prelazom na OM. Međutim, E postupak karakterišu mala brzina zavarivanja i veliki broj nastavaka, zbog zamene elektroda. Usled toga, zavarivanje se izvodi sa povećanim unosom toplote i sa ponovljenim zagrevanjem velikog broja mesta duž spoja, što pogoduje pojavi grešaka. Mala brzina zavarivanja i potreba za čišćenjem troske smanjuju produktivnost E postupka, pa ovaj postupak nije pogodan za zavarivanje cevi velikih prečnika.

TIG postupak omogućava zavarivanje korenog zavara sa malo grešaka formiranja šava. Međutim, postupak karakterišu mala brzina zavarivanja, relativno veliki broj nastavaka i potreba za dodatnom gasnom zaštitom naličja korena šava. I u ovom slučaju zavarivanje se izvodi sa povećanim unosom toplote i sa ponovljenim zagrevanjem relativno velikog broja mesta duž spoja, što pogoduje pojavi grešaka. Mala brzina zavarivanja smanjuje produktivnost postupka.

Prednosti MIG postupka, u odnosu na navedene postupke, jesu velika brzina zavarivanja, manji unos toplote i manji broj nastavaka. Zahvaljujući tome, moguće je izbeći, ili je u znatnoj meri moguće, smanjiti pojavu grešaka. Još jedna prednost MIG postupka je mogućnost kontinualnog merenja struje i napona tokom zavarivanja [3], što omogućava izračunavanje unete količine toplote na svakoj deonici spoja $i$, u slučaju pojave grešaka, njeno korigovanje. Nedostatak MIG postupka potreba je za dodatnom gasnom zaštitom naličja korena šava. Zbog velike brzine zavarivanja i relativno malog broja nastavaka, MIG postupak je najproduktivniji od svih navedenih postupaka, pa je najpogodniji za zavarivanje cevi od austenitnog čelika velikih prečnika.

Pri zavarivanju sučeonih spojeva na cevovodima, najsporije se zavaruju koreni prolazi. S obzirom na to, važno je razmotriti mogućnost ubrzavanja zavarivanja korenih prolaza primenom MIG postupka. Takođe, verovatnoća pojave grešaka u sučeonim spojevima najveća je u korenom prolazu, zbog čega se za zavarivanje ovog prolaza zahteva najveća veština zavarivača. Iz navedenih razloga razmotrena je mogućnost za povećanje brzine zavarivanja 
korenog prolaza uz održavanje potrebnog nivoa kvaliteta. Rešenje je pronađeno u zavarivanju softverski regulisanim modifikovanim lukom.

\section{SOFTVERSKI REGULISANI MODIFIKOVANI LUK}

Zavarivanje softverski regulisanim modifikovanim lukom [4] je postupak zavarivanja u modifikovanom režimu kratkospojenog prenosa. Ovaj postupak je namenski razvijen za zavarivanje korenih zavara [5].

$\mathrm{Na}$ Slici 2 data je promena jačine struje tokom prenosa jedne kapi pri zavarivanju modifikovanim lukom. U gornjem delu Slike 2 punom linijom je prikazana promena jačine struje u luku, a u donjem delu slike su prikazane različite faze gorenja luka.

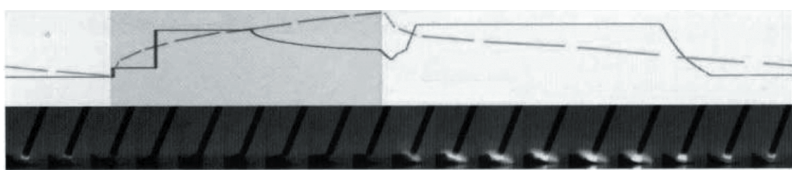

Slika 2. Promene jačine struje u različitim fazama gorenja softverski regulisanog modifikovanog luka.

Prenos svake kapi dodatnog materijala (DM) kroz modifikovani luk odvija u dve faze. U prvoj fazi, fazi kratkog spoja, proces počinje kratkim spojem između DM i tečnog kupatila. Ovaj kratki spoj praćen je malim porastom struje, plavo polje na Slici 2. Zatim sledi drugi veći porast jačine struje koji indukuje kontrakciju poprečnog preseka kapi na prelazu na neistopljeni DM, što omogućava njeno odvajanje od DM i slivanje u tečno kupatilo. Softver reguliše intenzitet i vreme trajanja struje kratkog spoja i momenat u kome struja počinje da se smanjuje. Na taj način ograničeno je zagrevanje kapljice DM i omogućen je njen prenos kroz luk bez pregrevanja, eksplozije i rasprskavanja. Zbog ovakvog načina prenosa, kap DM „meko” se sliva u tečno kupatilo.

Kada se kap DM slije u tečno kupatilo, počinje druga faza, faza gorenja luka. Ona je praćena porastom jačine struje. Intenzitet i vreme trajanja povećane jačine struje su softverski regulisani. Faza gorenja luka utiče na zagrevanje $\mathrm{OM}$, na oblik i dimenzije tečnog kupatila, na dubinu uvarivanja i na topljenje vrha DM. U ovoj fazi nema prenosa kapi DM. Posle stadijuma porasta sledi stadijum snižavanja struje do željenog baznog nivoa. Ovaj bazni nivo struje mora da bude optimalne veličine.
Suviše mala bazna struja onemogućava stabilno gorenje luka i topljenje vrha DM, a suviše velika bazna struja utiče da se prenos kapi DM menja iz kratkospojenog u krupnokapljičasti. Time se pogoršava formiranje korenog zavara, dobijaju se neujednačena širina i visina, pojavljuju se prokapine i pregreva se OM.

\section{Tehnika rada}

Postupak zavarivanja softverski regulisanim modifikovanim lukom može se koristiti za zavarivanje korenih zavara sa potpunim provarom, na limovima i na cevima. Nakon instalacije programa u uređaj za zavarivanje, zavarivač bira brzinu dodavanja žice, a program sam postavlja sve ostale parametre. Moguća je i ručna regulacija ukoliko je potrebna korekcija parametara npr. zbog suviše velikih ili suviše malih zazora u korenu žleba.

Softver za modifikaciju zavarivačkog luka može se koristiti samo na uređajima za zavarivanje koji imaju dovoljno brz i precizan odziv na promene napona luka. To su invertorski uređaji novijih generacija.

Zavarivanje modifikovanim lukom omogućava da se brzina zavarivanja korenog zavara poveća u odnosu na brzine zavarivanja korenih zavara zavarenih MIG, TIG i E postupcima. Zbog toga se dnevni obim zavarivačkih radova znatno povećava, naročito u poređenju sa E postupkom. Zbog bolje kontrole prenosa DM moguće je i smanjenje ugla žleba sa $60^{\circ}$ na $50^{\circ}$. To skraćuje vreme potrebno za zavarivanje. Odsustvo razbrizgavanja eliminiše troškove naknadne obrade površina OM. Ovo, sve ukupno, smanjuje troškove za rad pri izradi spoja.

Dodatne prednosti postupka zavarivanja modifikovanim lukom su još i zavarivanje bez razbrizgavanja, mogućnost premošćivanja širokih zazora u korenu žleba, dobro formiranje lica i naličja korenog prolaza, minimalne deformacije zbog malog unosa toplote i mogućnost zavarivanja u svim položajima.

Postupak zavarivanja modifikovanim lukom austenitnih visokolegiranih čelika može se primeniti za izradu cevovoda u postrojenjima za preradu pijaće vode, $u$ postrojenjima za preradu otpadnih voda, u hemijskoj industriji, $\mathrm{u}$ industriji prerade hrane. Takođe, ovaj postupak može se koristiti za izradu opreme pod pritiskom, za izradu skladišnih rezervoara i za izradu cisterni za transport u drumskom i železničkom saobraćaju.

\section{EKSPERIMENTALNI DEO}

Ispitni spoj zavaren je na cevi izrađenoj od čelika X5CrNi18-8 dimenzija 1220x8 mm. Hemijski sastav i 
mehanička svojstva ovog čelika date su u Tabelama 1 i 2. Kao DM korišćena je žica G199 LSi (EN 12072) prečnika $1 \mathrm{~mm}$. Hemijski sastav i mehanička svojstva DM dati su u Tabelama 3 i 4.

\begin{tabular}{ccccc}
\hline $\mathrm{C}$ & $\mathrm{Si}$ & $\mathrm{Mn}$ & $\mathrm{Cr}$ & $\mathrm{Ni}$ \\
\hline$\leq 0,07$ & $\leq 1,0$ & $\leq 2,0$ & $17,0-19,5$ & $8,0-10,5$ \\
\hline
\end{tabular}

Tabela 1. Hemijski sastav čelika X5CrNi 18-8.

\begin{tabular}{ccc}
\hline $\begin{array}{c}\text { Napon tečenja } \\
\mathrm{Rp} 0,2 \mathrm{MPa}\end{array}$ & $\begin{array}{c}\text { Zatezna čvrstoća } \\
\mathrm{Rm} \mathrm{MPa}\end{array}$ & $\begin{array}{c}\text { Izduženje } \\
\%\end{array}$ \\
\hline$\geq 230$ & $540-750 \geq 45$ & $\geq 45$
\end{tabular}

Tabela 2. Mehanička svojstva čelika X5CrNi 18-8.

\begin{tabular}{ccccc}
\hline $\mathrm{C}$ & $\mathrm{Si}$ & $\mathrm{Mn}$ & $\mathrm{Cr}$ & $\mathrm{Ni}$ \\
\hline$\leq 0,025$ & 0,8 & 2,0 & 19,0 & 9,0 \\
\hline
\end{tabular}

$\overline{\text { Tabela 3. Hemijski sastav dodatnog materijala G19 } 9 \text { LSi. }}$

\begin{tabular}{ccc}
\hline $\begin{array}{c}\text { Napon tečenja } \\
\mathrm{Rp} \mathrm{0,2} \mathrm{MPa}\end{array}$ & $\begin{array}{c}\text { Zatezna čvrstoća } \\
\mathrm{Rm} \mathrm{MPa}\end{array}$ & $\begin{array}{c}\text { Izduženje } \\
\mathrm{A} \%\end{array}$ \\
\hline$>320$ & $550-650$ & $>30$ \\
\hline
\end{tabular}

Tabela 4. Mehanička svojstva dodatnog materijala G19 9 LSi.
Korišćen je V žleb dimenzija datih na Slici 3. Kao zaštitni gas korišćena je mešavina $\mathrm{Ar}+3 \% \mathrm{CO} 2$ sa protokom od $15 \mathrm{l} / \mathrm{min}$, a za zaštitu korene strane šava korišćen je čist Ar sa protokom od 2 do $31 / \mathrm{min}$.

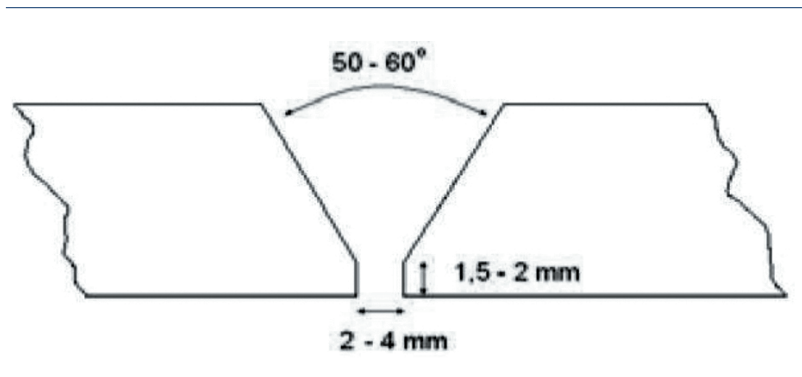

Slika 3. Oblik i dimenzije žleba korišćenog za izradu ispitnog spoja.

Ispitni spoj br. 1 zavaren je sa tri prolaza. Parametri zavarivanja dati su u Tabeli 5. Radi poređenja i ocene rezultata ispitivanja zavaren je i spoj br. 2 kod koga je koreni zavar zavaren klasičnim MIG postupkom. Parametri zavarivanja i ovog spoja dati su u Tabeli 5.

\section{REZULATI I DISKUSIJA}

Vizuelnim pregledom konstatovano je da je lice korenog prolaza spoja 1 ujednačene širine i bez grešaka formiranja šava. Visina lica menja se od blago ispupčenog

\begin{tabular}{|c|c|c|c|c|c|c|c|}
\hline $\begin{array}{l}\text { R. } \\
\text { br. }\end{array}$ & $\begin{array}{l}\text { Deo } \\
\text { spoja }\end{array}$ & $\begin{array}{l}\mathrm{I} \\
\mathrm{A}\end{array}$ & $\begin{array}{l}\mathrm{U} \\
\mathrm{V}\end{array}$ & $\begin{array}{c}\mathrm{V}_{\mathrm{z}} \\
\mathrm{cm} / \mathrm{min}\end{array}$ & $\begin{array}{c}\mathrm{V}_{\mathrm{z}} \\
\mathrm{mm} / \mathrm{sec}\end{array}$ & $\begin{array}{c}\mathrm{Q} \\
\mathrm{KJ} / \mathrm{mm} \\
*\end{array}$ & $\begin{array}{c}\text { Postupak } \\
\text { zavarivanja }\end{array}$ \\
\hline \multirow{3}{*}{$\begin{array}{c}\text { Spoj } \\
1\end{array}$} & Koren & 90,1 & 19,5 & 13,9 & 2,32 & 0,61 & $\begin{array}{l}\text { Modifikovani } \\
\text { luk }\end{array}$ \\
\hline & Popuna & 132,1 & 23,1 & 17,0 & 2,83 & 0,86 & MIG \\
\hline & Lice & 141,5 & 23,4 & 16,3 & 2,72 & 0,97 & MIG \\
\hline \multirow{3}{*}{$\begin{array}{l}\text { Spoj } \\
2\end{array}$} & Koren & 83,2 & 19,9 & 6,37 & 1,06 & 1,25 & MIG \\
\hline & Popuna & 130,9 & 23,1 & 17,6 & 2,93 & 0,83 & MIG \\
\hline & Lice & 135,8 & 23,2 & 15,3 & 2,55 & 0,99 & MIG \\
\hline
\end{tabular}

Tabela 5. Parametri zavarivanja.

${ }^{\star}$ za MIG postupak $\eta=0,8$

u horizontalnom i vertikalnom delu spoja do ispupčenijeg u nadglavnom delu spoja. Pregled naličja korenog prolaza pokazuje da je celom dužinom spoja postignut potpuni provar ujednačene visine i širine. Radiografskim ispitivanjem $\mathrm{i}$ ispitivanjem penetrantima ovog spoja nisu otkrivene prsline niti druge greške formiranja u šavu i njegovoj okolini.

Zatezne karakteristike MŠ određene su ispitivanjem okruglih epruveta (Ø6 mm). Rezultati ispitivanja dati su u Tabeli 6. 


\begin{tabular}{|c|c|c|c|c|c|c|}
\hline \multirow{2}{*}{$\begin{array}{l}\text { Epruveta } \\
\text { br. }\end{array}$} & \multicolumn{2}{|c|}{ Napon tečenja } & \multicolumn{2}{|c|}{$\begin{array}{c}\text { Zatezna čvrstoća } \\
\mathrm{Rm} \mathrm{MPa}\end{array}$} & \multicolumn{2}{|c|}{$\begin{array}{c}\text { Izduženje } \\
\text { A \% }\end{array}$} \\
\hline & Pojedinačno & Srednja vrednost & Pojedinačno & Srednja vrednost & Pojedinačno & Srednja vrednost \\
\hline 1 & 321 & \multirow{3}{*}{324} & 612 & \multirow{3}{*}{625} & 37 & \multirow{3}{*}{37} \\
\hline 2 & 321 & & 626 & & 37 & \\
\hline 3 & 331 & & 636 & & 36 & \\
\hline
\end{tabular}

Tabela 6. Rezultati ispitivanja zateznih karakteristika metala šava.

Ispitivanje savijanjem epruveta sa spojem u celini uradeno je na epruvetama sa paralelnim bokovima. Rezultati ispitivanja pokazali su da je ugao savijanja kod svih ispitivanih epruveta $180^{\circ}$ i da nije utvrđeno prisustvo prslina.

$\mathrm{Na}$ Slici 4 prikazana je mikrostruktura MŠ. Uočava se austenitna mikrostruktura sa udelom $\delta$ - ferita, koji je uobičajen za spoj zavaren DM G 199 L Si.

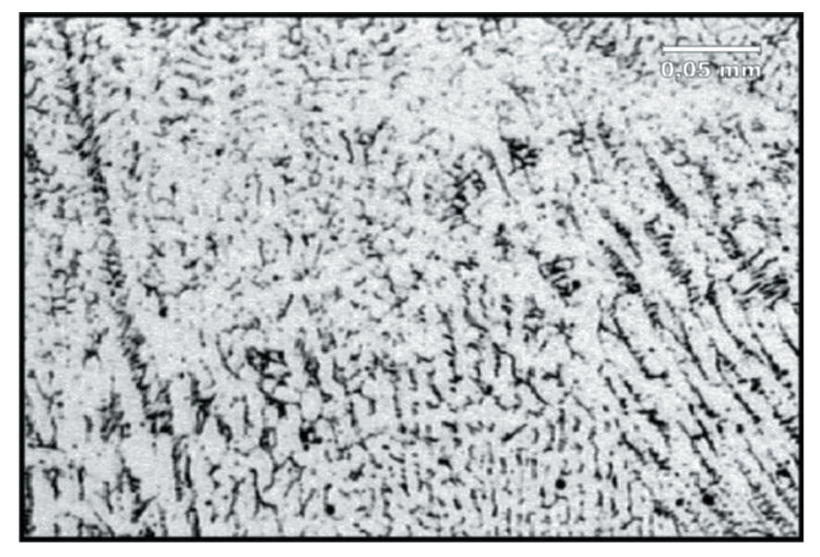

$200 x$

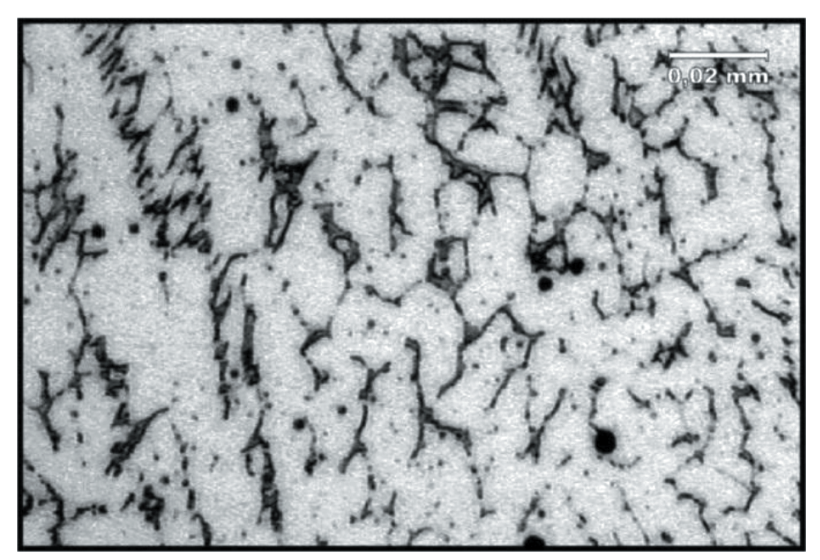

$500 \mathrm{x}$

Slika 4. Mikrostruktura metala šava: osnova austenita sa udelom $\delta$ - ferita
Rezultati ispitivanja na savijanje i ispitivanja mikrostruktura pokazuju da usvojena tehnologija zavarivanja ne dovodi do pojave toplih prslina i prslina usled interkristalne korozije. Mikrostrukturnim ispitivanjem nije uočeno izlučivanje karbida hroma po granicama zrna. Ugao savijanja epruveta od $180^{\circ}$ bez pojave prslina i sa strane lica i sa strane korena spoja govori da je materijal MŠ i ZUT dovoljno plastičan tj. da se u spoju nisu pojavile krte faze.

Rezultati iz Tabele 5 pokazuju da je brzina zavarivanja korenog prolaza modifikovanim lukom više nego dvostruko veća u odnosu na zavarivanje korenog prolaza klasičnim MIG postupkom. Do sada su za zavarivanje korenih prolaza na cevima izrađenim od austenitnih nerđajućih čelika uglavnom korišćeni TIG i E postupci kod kojih je brzina zavarivanja manja u odnosu na klasični MIG postupak. Primenom modifikovanog luka, umesto TIG i E postupaka, brzine zavarivanja korenih prolaza mogu se još više povećati. S obzirom na to da je zavarivanje korenog prolaza najsporija faza u izradi zavarenog spoja, njeno ubrzavanje skraćuje i vreme izrade spoja u celini [6]. Na taj način, primenom modifikovanog luka dnevni obim zavarivačkih radova može da se poveća u odnosu na primenu klasičnog MIG postupka za oko 17\%, u odnosu na primenu TIG postupka za oko $30 \%$, i u odnosu na primenu E postupka za 70 do $80 \%$ [7].

\section{ZAKLJUČAK}

U radu je pokazano kako se putem softvera može upravljati promenama jačine struje i napona tokom prenosa svake pojedinačne kapi kroz zavarivački luk. Primena softverske regulacije na uređajima za zavarivanje otvara nove i široke mogućnosti u oblasti razvoja tehnologije zavarivanja. Softverskom regulacijom može se uticati na kinetiku prenosa dodatnog materijala kroz luk, toplotne i metalurške procese u luku i osnovnom materijalu i na pojavu grešaka u zavarenim spojevima. Time se, $\mathrm{u}$ suštini, povećava kvalitet zavarenih spojeva i proširuju 
se tehnološke mogućnosti za primenu postupaka zavarivanja. Softverska regulacija luka utiče i na produktivnost procesa zavarivanja kroz povećanje brzine zavarivanja i smanjenje utroška vremena na prateće operacije, kao što je npr. uklanjanje troske i brušenje nastavaka. Obuka zavarivača za zavarivanje modifikovanim lukom MIG postupkom jednostavnija je i time i jeftinija nego npr. obuka za zavarivanje TIG i E postupcima. Nedostatak postupka zavarivanja sa softverskom regulacijom luka relativno je visoka cena uređaja za zavarivanje, koja se kreće u nivou cena skupljih TIG uređaja. Međutim, visoka produktivnost postupka garantuje otplatu uređaja u razumnom roku.

\section{ZAHVALNOST}

Ovaj rad proistekao je iz rezulatata istraživanja na projektu Ministarstva prosvete, nauke i tehnološkog razvoja Republike Srbije TR 35024.

\section{LITERATURA}

[1] H. Šuman, Metalografija, Tehnološko metalurški fakultet, Beograd, 1981.

[2] I. Hrivnjak, Zavarljivost čelika, Građevinska knjiga, Beograd, 1982.

[3] U. Lukić, R. Prokić Cvetković, O. Popović, R. Jovičić, B. Zrilić: Obezbeđenje kvaliteta zavarenih spojeva na osnovu praćenja parametara zavarivanja u realnom vremenu, Sinteza 2014, Impact of Internet on Business Activities in Serbia and Worldwide, Singidunum University, 25.-26.04.2014. Beograd, Republika Srbija. str. 937-940

[4] B. Zrilić, N. Pantelić, R. Jovičić, D. Jovičić: Inovacije u tehnologiji zavarivačkog luka, Zavarivanje i zavarene konstrukcije, Vol 57, No 4 (2012), str. 163 -167,

[5] J. Kumpulainen, The revolution in MAG welding of root passes, ProNews 2013, Kemppi, Lahti, Finland, 2013.

[6] R. Jovičić, D. Pavlović, B. Zrilić, N. Pantelić, J. Markež: Napredne tehnologije zavarivanja - zavarivanje modifikovanim lukom, "ZAVARIVANJE 2016", Zbornik sa 29. savetovanja sa međunarodnim učešćem, 14-17. septembar 2016., Srebrno jezero, Republika Srbija, str. 35 - 43,

[7] E. Belinga, Applications and Benefits of Adaptive Pulsed GMAW, Master Theses, Lappeenrata University of Technology, Faculty og Technology, Finland, 2012. 